\title{
On the Effects of Burnishing Process on Tribological Surface Resistance of Additively Manufactured Steel
}

\author{
Maria Rosaria Saffioti, Michela Sanguedolce, Giovanna Rotella and Luigino Filice
}

\author{
Maria Rosaria Saffioti. Department of Mechanical, Energy and Management Engineering, University of Calabria, Rende, CS \\ 87036, Italy \\ Michela Sanguedolce. Department of Mechanical, Energy and Management Engineering, University of Calabria, Rende, CS 87036, \\ Italy \\ Giovanna Rotella. Department of Engineering for Innovation, University of Salento, Lecce, LE 73100, Italy \\ Corresponding author: giovanna.rotella@unical.it
}

Luigino Filice. Department of Mechanical, Energy and Management Engineering, University of Calabria, Rende, CS 87036, Italy

\begin{abstract}
Burnishing is a Severe Plastic Deformation process having the potential to replace expensive finishing post processes. It is considered a super finishing process due to its results in terms of drastic roughness reduction. Also, additional advantages include the surface integrity improvement functionalized to the specific application. Even though burnishing is widely applied for surface improvement of conventional materials, knowledge about its effect on additively manufactured metals is still limited. This paper aims to fill this gap presenting experiments on roller burnishing on additively manufactured stainless steel in order to improve its tribological performance. The experimental campaign was carried out to find suitable process parameters able to drastically improve the tribological behavior of the final product. In particular, the influence of the burnishing forces on the whole surface quality has been addressed. The overall results demonstrate that the selected burnishing configuration is able to successfully modify the surface characteristics of the steel, making it appropriate for critical applications. Furthermore, the experimental findings allow to conclude that burnishing process can replace a series of post processes needed after additive manufacturing, drastically reducing the time and costs associated to the manufacturing process and meeting Industry 4.0 requirements.
\end{abstract}

Keywords. Additive Manufacturing, Machining, Severe Plastic Deformation, Burnishing, Tribology

\section{Introduction}

Additive manufacturing (AM), unlike conventional manufacturing, allows the production of near-net-shape products in a single step, suppressing intermediate component relocation steps from a machine to another and bringing significant cost drop in case of high-complexity parts [1]. Also, the fact that waste of raw materials is minimized is a major benefit.

On the other hand, AM may result in low reliability components which turn out to be unsafe, especially for critical applications involving severe working environments such as aerospace, marine and biomedical ones. In fact, AM products can suffer from poor surface integrity, surface quality, lack of accuracy, detrimental residual stresses etc. [2].

More in detail, typical issues concern (i) the presence on surface of stair-steps, adhered powder and residuals from support removal, (ii) poor accuracy related to positioning limitations of machines, shrinkage and residual stress-induced distortion, (iii) porosity arising from reduced bonding between particles/layers, (iv) anisotropy in microstructure and mechanical properties $[2,3]$. These metallurgical faults, such as pores together with the molten pool boundaries, are preferred sites for localized corrosion [4]. They also can decrease the ability of the alloy in forming a protective oxide layer, acting as traps for liquid solution in working environment.

Porosity of the part can be improved up to a certain point by optimizing printing parameters but, even if minimum in size and percentage, it has been found that inferior fatigue and tribocorrosion performance of AM metallic parts can be connected to inherent porosity coming from manufacturing process [5]. Also, performances of AM components are 
On the Effects of Burnishing Process on Tribological Surface Resistance of Additively M...

affected by distinct structures with respect to conventionally manufactured ones, related to different cooling rates and some unwanted phases which might be formed.

For the above-mentioned reasons, post-processing operations are often mandatory. Post-processing includes thermal treatment (for residual stress, porosity reduction, microstructure improvement), sand blasting, machining, polishing, shoot peening etc.

Within surface and subsurface modification processes which can be employed, burnishing and machine hammer peening aim to modify surface quality and near surface structure by severe plastic deformation (SPD).

In particular, burnishing is a cold working chipless process involving the rubbing of a hardened tool on component surface applying a specified pressure, in order to smooth roughness and depress surface asperities. It enables product functionalization through improvement of surface roughness, introduction of beneficial compressive residual stresses, strain hardening and grain refinement.

It has been demonstrated that these modifications can lead to enhanced mechanical properties, fatigue life, wear and corrosion resistance [6], that burnishing can succeed in replacing other finishing processes [7, 8] and recent developments concern its application to complex-shaped parts [9]. It also carries along an added value related to low costs and easiness of process implementation.

As mentioned before, AM is becoming increasingly requested and quality of parts is relevant in various industries such as the ones employing stainless steels (SS). These alloys are extensively used for construction, medical instrumentation, automotive, aerospace, marine applications etc. which often involve tribocorrosive working conditions. Their corrosion performance heavily relies on growth and stability of a passive film, depending on several parameters such as alloy microstructure, falling within the above cases. Within this framework, optimization of printing and post-processing conditions is a current concern in order to accommodate Industry 4.0 requirements in terms of growing product customization necessities.

The material object of this work is additively manufactured GP1, a precipitation hardening stainless steel used in marine applications because of its duplex microstructure of combined martensite and austenite [10].

Components have been manufactured employing a laser powder bed fusion process (L-PBF), which involves the use of laser to selectively melt metal powder located within a powder bed, delivered on a substrate plate by means of a roller. The analysis of tribological behaviour has been carried out in saline conditions [11,12] in order to assess the performance of surface modified samples through machining and burnishing with respect to as printed ones, using the same material as counterpart in line with studies in literature $[9,10]$.

\section{Materials and Methods}

The material studied in this work is Stainless Steel (SS) GP1. Samples have been additively manufactured in the shape of round bars with build direction normal to the sintering plate. A laser powder bed fusion (L-PBF) process has been employed, using building parameters optimized by the manufacturer of the printer EOSINT M 270, EOS GmbH. After removal from the sintering plate, a stress relieving heat treatment has been performed according to manufacturer's suggestions at $650^{\circ} \mathrm{C}$ for 1 hour.

The samples have been then machined at roughing parameters $(0.25 \mathrm{~mm}$ depth of cut, $0.2 \mathrm{~mm} / \mathrm{rev}$ feed rate and $5 \mathrm{~m} /$ min speed) to remove poor quality outer layers and prepare the surface for subsequent burnishing process.

Roller burnishing process has been carried out on curved surfaces in force feedback control using a Kistler 9257 
three-component piezoelectric dynamometer and adjusting tool configuration in order to achieve the desired force.

The experimental campaign has been performed under minimum quantity of lubrication conditions (MQL), as the complete absence of cooling/lubrication may result in poor surface finish and accelerated tool wear; temperature throughout the process has been monitored through an infrared thermo-camera and it always remained below $30^{\circ} \mathrm{C}$. Burnishing parameters have been selected in two different combinations, according to best and worst cases from the experimental campaign in [10] and are reported in Table 1. In fact, it has been found that lower component quality was related to low burnishing force, tool radius value, feed rate and burnishing speed (Burnishing condition 1 - B1) while best results in terms of surface roughness $\mathrm{Ra}$, residual stresses and hardness were achieved combining high burnishing force, tool radius value, feed rate and burnishing speed (Burnishing condition 2 - B2).

Table 1. Burnishing parameters employed for the experimental campaign

\begin{tabular}{cll}
\hline Burnishing parameter & B1 & B2 \\
\hline Force $F[\mathrm{~N}]$ & 1000 & 2000 \\
Feed $f[\mathrm{~mm} / \mathrm{rev}]$ & 0.05 & 0.1 \\
Speed $v[\mathrm{~m} / \mathrm{min}]$ & 50 & 150 \\
Tool radius $R[\mathrm{~mm}]$ & 2.5 & 5 \\
\hline
\end{tabular}

Cylindrical samples and counterparts have been obtained from SS GP1 bars of different diameters. In particular, burnished samples of $5 \mathrm{~mm}$ thickness have been obtained from round bars having diameter of $15 \mathrm{~mm}$ while counterparts have been obtained from $30 \mathrm{~mm}$ diameter round bars and their surface was ground to achieve $0.1 \mu \mathrm{m}$ Ra. Roughness Ra of as printed, as turned and burnished specimens, measured along the feed direction, is reported in Table 2.

Tribological tests have been performed in cylinder-on-disk configuration in single way rotary mode, in corrosive environment, using a DTRB 70090 tribometer by CSM Instruments. Tribological behavior of burnished samples has been compared to as turned and as printed ones in tribocorrosive conditions, using $0.6 \mathrm{M} \mathrm{NaCl}$ solution [11]. Testing parameters have been selected according to preliminary tests and literature [15] choosing $5 \mathrm{~N}$ as normal load, $0.1 \mathrm{~m} / \mathrm{s}$ for sliding velocity, $10 \mathrm{~mm}$ for sliding radius and 30000 for number of laps. Two repetitions have been performed for each test. Samples have been cleaned before and after each test, using compressed air and ultrasonic cleaner, employing acetone as agent. Coefficient of friction $\mu$ has been calculated according to equation (1), for known normal load and measured tangential friction force and resulting curves have been filtered into tribometer proprietary software.

$$
\mu=\frac{\text { Friction Force }[N]}{\text { Normal Load }[N]}
$$

While specific wear rate (SWR) has been estimated according to [16], using equation (2), weighing samples before and after each test using a balance with $0.01 \mathrm{mg}$ sensitivity.

$$
S W R=\frac{\text { Volume loss }\left[\mathrm{mm}^{3}\right]}{\text { Normal Load }[\mathrm{N}] \cdot \text { Sliding Distance }[\mathrm{m}]}
$$


On the Effects of Burnishing Process on Tribological Surface Resistance of Additively M...

Table 2. Mean roughness of tested samples

\begin{tabular}{cllll}
\hline Specimen & $\begin{array}{l}\text { As printed } \\
\text { (AP) }\end{array}$ & $\begin{array}{l}\text { As turned } \\
\text { (AT) }\end{array}$ & $\begin{array}{l}\text { Burnishing } \\
\text { condition 1 } \\
\text { (B1) }\end{array}$ & $\begin{array}{l}\text { Burnishing } \\
\text { condition 2 } \\
\text { (B2) }\end{array}$ \\
\hline$R a[\mu \mathrm{m}]$ & 11 & 0.74 & 0.32 & 0.18 \\
\hline
\end{tabular}

\section{Results and Discussion}

Results from tribological tests revealed the possibility to improve wear resistance in tribocorrosive environment for additively manufactured steels using burnishing process. In fact, as reported in Figure 1 and 2, in the case of burnished samples specific wear rate, for both samples and counterparts, results reduced. More in detail, combining removal of low-quality outer layers and subsequent burnishing brought to a specific wear rate (result of synergistic effect between corrosion and wear) reduction up to $71 \%$ with respect to as printed samples, in comparison with the $40 \%$ given by the sole machining.

The reasons for this improvement can be found in residual stresses and surface integrity enhancement induced by burnishing process, together with different contact area related to surface finish.

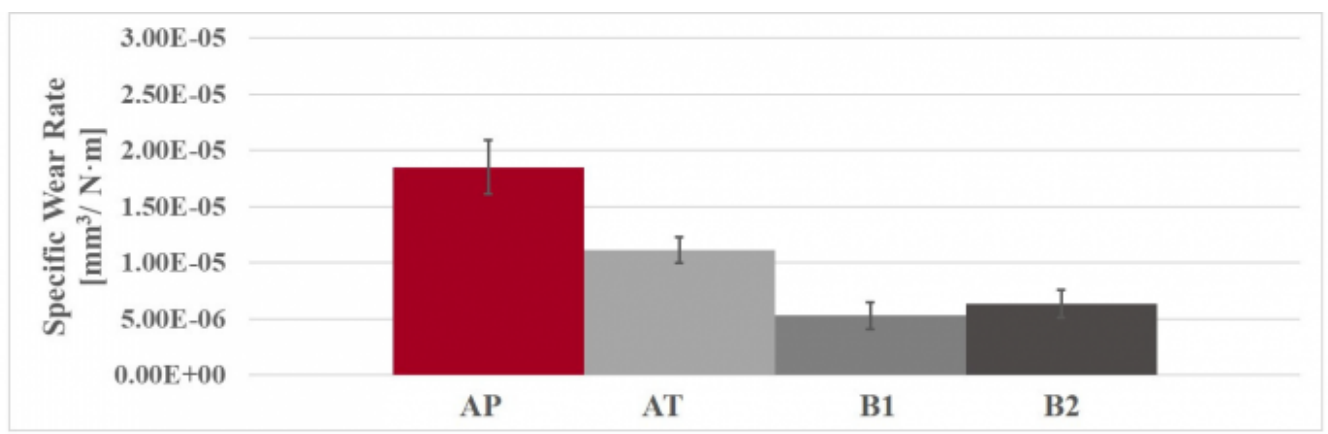

Fig. 1. Specific Wear Rate for tested samples

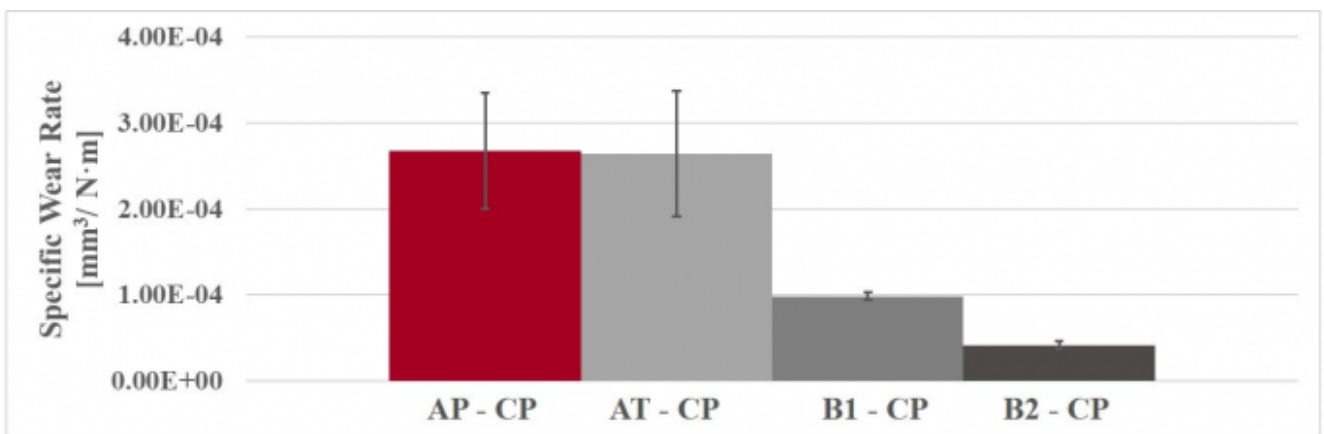

Fig. 2. Specific Wear Rate for ground counterparts sliding against different samples 
In fact, friction is a result of multiple interactions between contacting bodies, related to various contributes. These contributes include adhesion, mechanical deformation and plowing. The first one is related to shearing of adhesive junctions formed between contacting surfaces and, in liquid mediated contact, also to viscous and meniscus forces (provided the formation of menisci). The second one is due to mechanical deformation occurring at points of contact. The third one consists in plowing of harder material into the surface of softer material. Frictional components depend on real area of contact during sliding, together with other factors.

Adhesion component of friction is proportional to real area of contact (contacting spots) then it decreases with increasing surface roughness, while the mechanical deformation becomes larger as the real area of contact decreases. [17-19]

Under these particular conditions, smaller contact area in the case of as printed samples can lead to more severe loading conditions, due to higher local contact pressures, thus bringing to increased friction coefficient and wear. This occurrence manifests itself in a lesser extent for machined samples, significantly reducing for burnished samples, regardless of burnishing conditions tested.

In terms of friction coefficient, it can be seen that a steady value is reached within 10000 laps, with some fluctuations and peaks that can be attributed to the formation and removal of wear debris. Also, discontinuity in cyclic formation of surface oxides may be the reason of sudden drops in friction.

A difference of coefficient of friction can be recognized only in the case of as printed samples with respect to machined and burnished ones; no significant influence of burnishing process with respect to the sole machining can be seen, apart from a mild delay in initial surface degradation during running in phase for B2 condition, as highlighted in Figure 3.

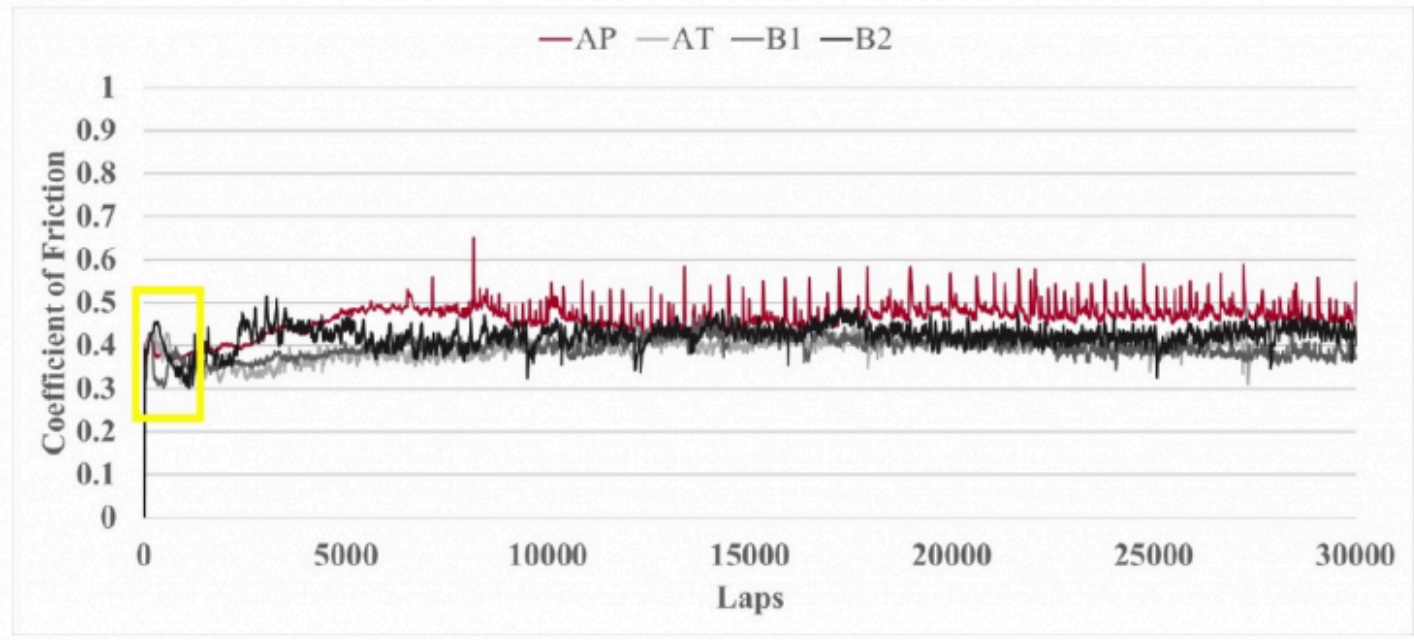

Fig. 3. Coefficient of friction from one group of performed tests

As a means of comparison, surface of samples before tribological tests is shown in Figure 4. From the observation of worn-out surfaces of samples (Fig. 5) and counterparts (Fig. 6), grooves parallel to sliding direction can be recognized; these are due to penetration of asperities from the mating part. Two-body abrasive wear is more pronounced in the case of as printed samples, of which surface asperities due to high roughness penetrate into the surface of counterpart (Fig. 6a) and it is also a reason for friction force increase due to plowing.

On the other hand, adhesive wear (also due to metallurgical compatibility) and pitting is more marked for tests 
On the Effects of Burnishing Process on Tribological Surface Resistance of Additively M...

involving machined samples with respect to burnished ones, thus implying an improvement of performances due to superfinishing burnishing process. In fact, it has been recognized that severe plastic deformation processes, introducing strain hardening and residual stresses can provide a better resistance to cracking in corrosive environments $[15,16]$. The formation and breaking of oxide layers have been recognized throughout the tests and residuals have been found into saline solution at the end of the tests.
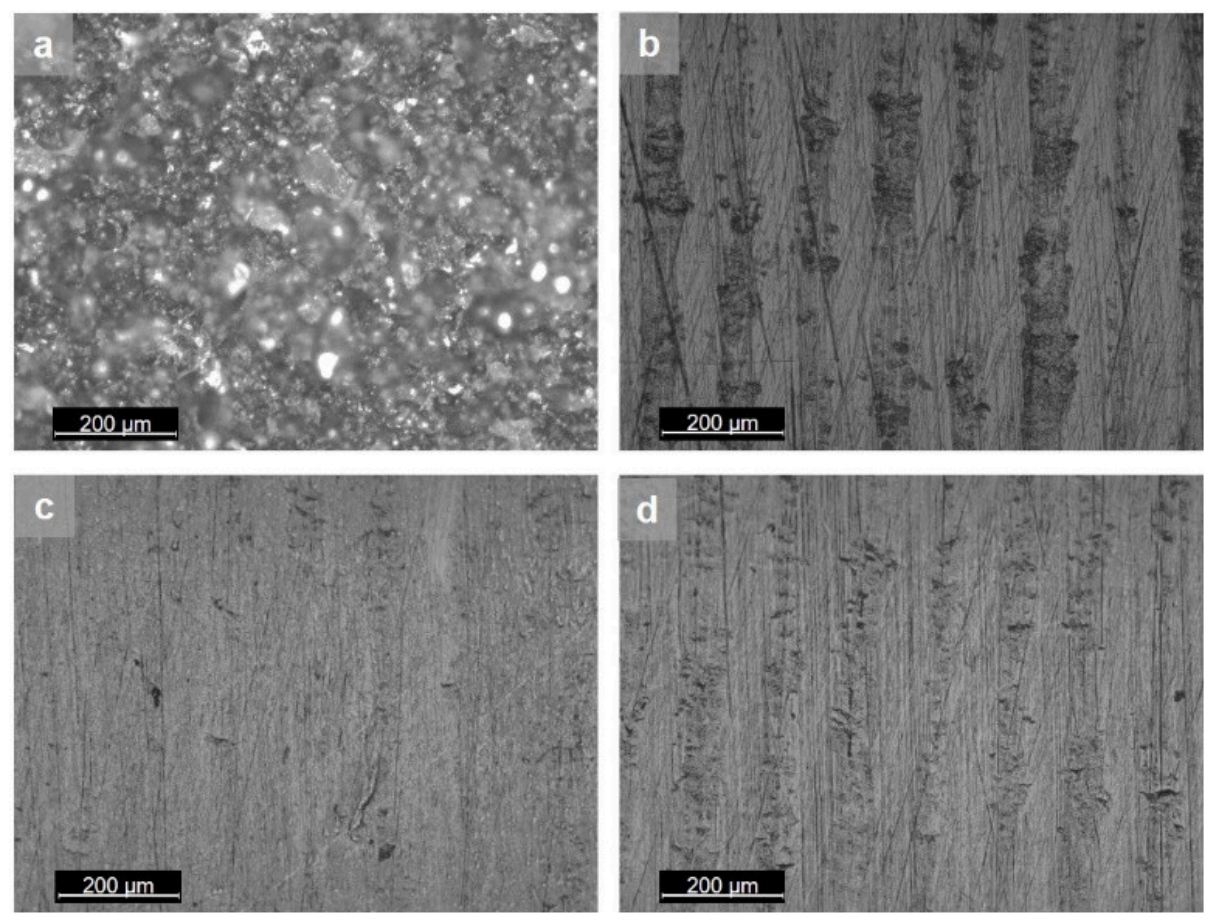

Fig. 4. Surface of a) as printed, b) as turned, c) burnished condition 1, d) burnished condition 2 samples before the tests 

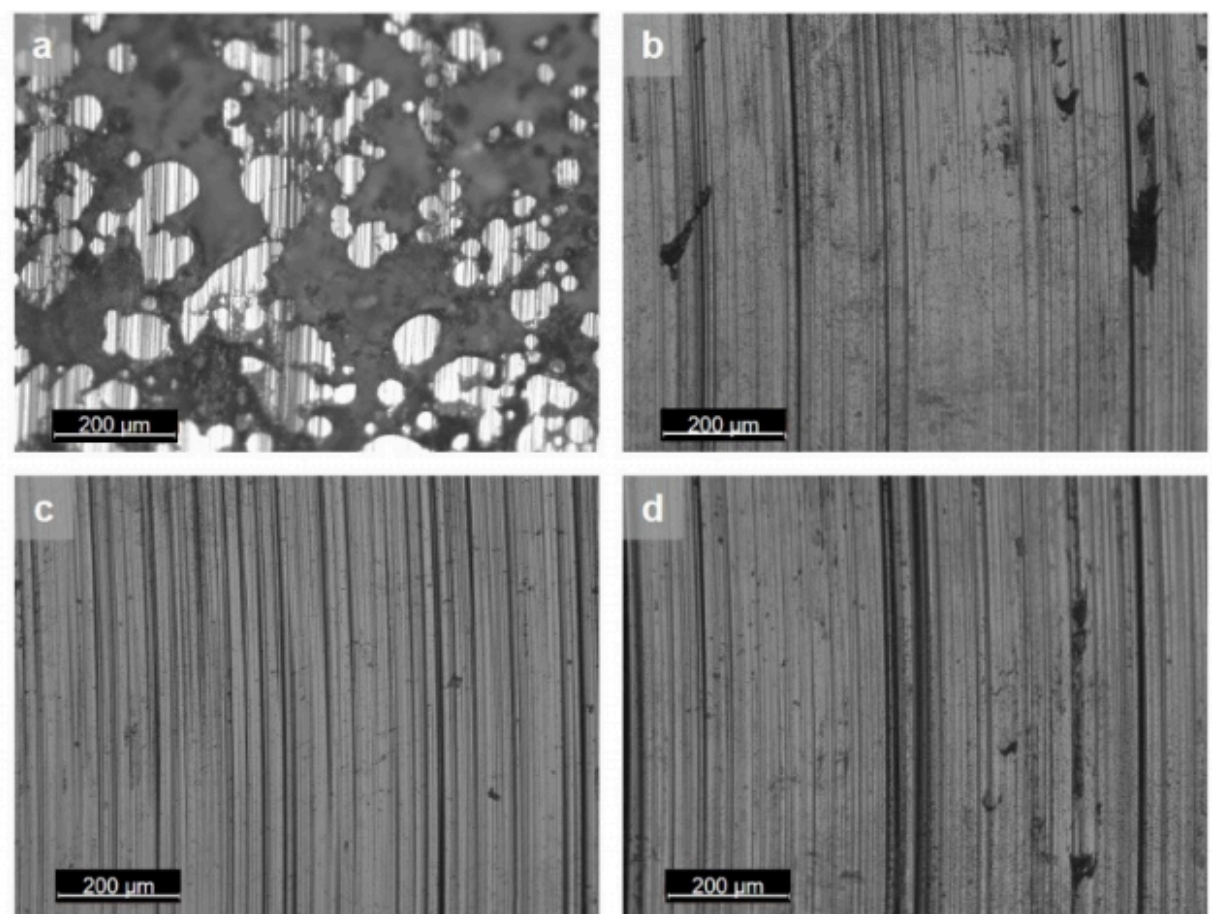

Fig. 5. Worn-out surface of a) as printed, b) as turned, c) burnished condition 1, d) burnished condition 2 samples
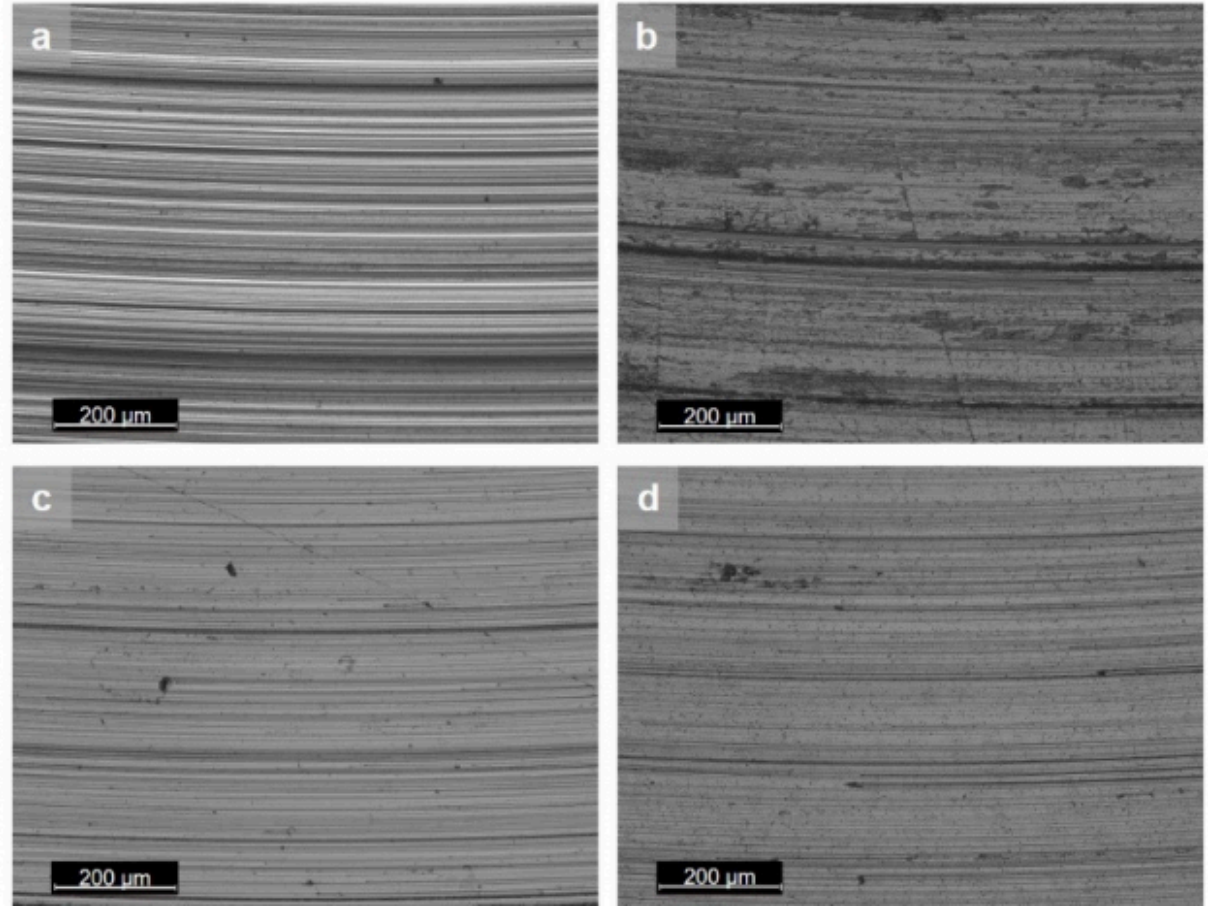

Fig. 6. Worn-out surface of counterparts for a) as printed, b) as turned, c) burnished condition 1, d) burnished condition 2 samples 
On the Effects of Burnishing Process on Tribological Surface Resistance of Additively M...

\section{Conclusions}

Producing components through 3D printing paved the way for a new paradigm in terms of mass production, including advantages related to invariance of costs regardless of product complexity. But the low reliability issues related to additively manufactured components still need to be faced to safely fully introduce these techniques into application fields involving severe working environments. In fact, defects originating from manufacturing process represent a risk of catastrophic failure in operating phase.

Hence, the growing effort in introducing and optimizing post-processing operations in order to overcome these issues and trying to retain the advantages of AM.

SPD processes represent one of the available solutions, in terms of strength, fatigue life and corrosion resistance improvement of components. Burnishing is one of the representatives of this category of secondary processes, distinguishing itself for low costs and easiness of implementation. It has been previously tested for fatigue life improvement of additively manufactured steels revealing promising results; as complementary tests, tribocorrosion performance enhancement has been assessed in order to promote a comprehensive view of this process applied to additively manufactured parts.

The experimental campaign, executed for comparative purposes, confirms the possibility to successfully improve component behaviour and delay its failure in tribocorrosive environments, reducing wear entity thanks to the reduction of surface roughness, introduction of beneficial compressive residual stresses and strain hardening. Overall results encourage cost cutting and easiness in implementation of novel process chains, involving processes for near-net-shape production without compromising reliability of components. Also, the use of minimum quantity lubricant conditions instead of flood ones fits the shift towards environmentally friendly development.

\section{Bibliography}

[1] Fera, M., Macchiaroli, R., Fruggiero, F., Lambiase, A., A new perspective for production process analysis using additive manufacturing-complexity vs production volume, Int. J. Adv. Manuf. Technol. (2018) 95 673-685. https://doi.org/ 10.1007/s00170-017-1221-1.

[2] Abdulhameed, O., Al-Ahmari, A., Ameen, W., Mian, S.H., Additive manufacturing: Challenges, trends, and applications, Adv. Mech. Eng. (2019) 11 1-27. https://doi.org/10.1177/1687814018822880.

[3] Gibson, I., Rosen, D., Stucker, B., Additive manufacturing technologies: 3D printing, rapid prototyping, and direct digital manufacturing, second edition, 2015. https://doi.org/10.1007/978-1-4939-2113-3.

[4] Kong, D., Ni, X., Dong, C., Zhang, L., Man, C., Yao, J., Xiao, K., Li, X., Heat treatment effect on the microstructure and corrosion behavior of 316L stainless steel fabricated by selective laser melting for proton exchange membrane fuel cells, Electrochim. Acta. (2018) 276 293-303. https://doi.org/10.1016/j.electacta.2018.04.188.

[5] Stendal, J., Fergani, O., Yamaguchi, H., Espallargas, N., A Comparative Tribocorrosion Study of Additive Manufactured and Wrought 316L Stainless Steel in Simulated Body Fluids, J. Bio- Tribo-Corrosion. (2018) 4 1-10. https://doi.org/ $10.1007 /$ s40735-017-0125-9.

[6] Schulze, V., Bleicher, F., Groche, P., Guo, Y.B., Pyun, Y.S., Surface modification by machine hammer peening and burnishing, CIRP Ann. - Manuf. Technol. (2016) 65 809-832. https://doi.org/10.1016/j.cirp.2016.05.005.

[7] Salmi, M., Huuki, J., Ituarte, I.F., The ultrasonic burnishing of cobalt-chrome and stainless steel surface made by additive manufacturing, Prog. Addit. Manuf. (2017) 2 31-41. https://doi.org/10.1007/s40964-017-0017-z. 
[8] Delgado, P., Cuesta, I.I., Alegre, J.M., Díaz, A., State of the art of Deep Rolling, Precis. Eng. (2016) 46 1-10. https://doi.org/10.1016/j.precisioneng.2016.05.001.

[9] De Lacalle, L.N.L., Rodriguez, A., Lamikiz, A., Celaya, A., Alberdi, R., Five-axis machining and burnishing of complex parts for the improvement of surface roughness, Mater. Manuf. Process. (2011) 26 997-1003. https://doi.org/10.1080/ 10426914.2010 .529589$.

[10] Rotella, G., Filice, L., Micari, F., Improving surface integrity of additively manufactured GP1 stainless steel by roller burnishing, CIRP Ann. (2020) 69 513-516. https://doi.org/10.1016/j.cirp.2020.04.015.

[11] Schaller, R.F., Taylor, J.M., Rodelas, J., Mishra, A., Schindelholz, E.J., Corrosion Properties of Powder Bed Fusion Additively Manufactured 17-4 PH Stainless Steel, Mater. Sci. Technol. Conf. Exhib. 2017, MS T 2017. (2017) 2 10831085. https://doi.org/10.7449/2017/MST-2017-1083-1085.

[12] Laleh, M., Hughes, A.E., Xu, W., Cizek, P., Tan, M.Y., Unanticipated drastic decline in pitting corrosion resistance of additively manufactured 316L stainless steel after high-temperature post-processing, Corros. Sci. (2020) 165108412. https://doi.org/10.1016/j.corsci.2019.108412.

[13] Lei, M.K., Zhou, Q., Ou, Y.X., Song, T.K., Guo, Y., Tribological behaviour of plasma based low energy nitrogen ion implanted AISI 316 austenitic stainless steel against same stainless steel counterface, Surf. Eng. (2013) 26 277-283. https://doi.org/10.1179/026708410x12671039164606.

[14] Ausserer, F., Klien, S., Velkavrh, I., Diem, A., Investigations of the sliding and wear behaviour in various gaseous atmospheres using a SRV testing apparatus, Tribol. Und Schmierungstechnik. (2016) 63 22-28.

[15] Meng, J., Loh, N.H., Tay, B.Y., Fu, G., Tor, S.B., Tribological behavior of 316L stainless steel fabricated by micro powder injection molding, Wear. (2010) 268 1013-1019. https://doi.org/10.1016/j.wear.2009.12.033.

[16] ASTM, G99. Standard Test Method for Wear Testing with a Pin-on-Disk Apparatus, ASTM Int. West Conshohocken, PA. (2016) G99 1-5. https://doi.org/10.1520/G0099-05R10.2.

[17] Bushan, B., Introduction to tribology, Second Edition, John Wiley \& Sons, Ltd., 2013.

[18] Chen, G.S., Fundamentals of contact mechanics and friction, Woodhead Publishing, 2014. https://doi.org/10.1533/ 9780857094599.71.

[19] Rashwan, O., Micro Surface Texturing for Friction Control, Univ. Wind. (Ontario, Canada). (2013).

[20] Mordyuk, B.N., Prokopenko, G.I., Vasylyev, M.A., Iefimov, M.O., Effect of structure evolution induced by ultrasonic peening on the corrosion behavior of AISI-321 stainless steel, Mater. Sci. Eng. A. (2007) 458 253-261. https://doi.org/ 10.1016/j.msea.2006.12.049.

[21] Hilpert, M., Wagner, L., Corrosion fatigue behavior of the high-strength magnesium alloy AZ 80, J. Mater. Eng. Perform. (2000) 9 402-407. https://doi.org/10.1361/105994900770345791.

PDF automatically generated on 2021-05-20 11:33:39

Article url: https://popups.uliege.be/esaform21/index.php?id=1903

published by ULiège Library in Open Access under the terms and conditions of the CC-BY License (https://creativecommons.org/licenses/by/4.0) 